\title{
Budget impact analysis of apixaban versus other NOACs for the prevention of stroke in Italian atrial fibrillation patients
}

\author{
Lorenzo Pradelli ${ }^{1}$, Mario Calandriello ${ }^{2}$, Roberto Di Virgilio ${ }^{3}$, Marco Bellone ${ }^{1}$, \\ Marco Tubaro ${ }^{4}$ \\ AdRes, Health Economics \& Outcome Research, Turin, Italy \\ Bristol-Myers Squibb Italy, Rome, Italy \\ Pfizer Italy, Rome, Italy \\ ${ }^{4}$ ICCU, Cardiovascular Department, San Filippo Neri Hospital, Rome, Italy
}

\begin{abstract}
OBJECTIVE: This study aims to perform a budget impact analysis of the use of three available novel oral anticoagulant agents (NOACs) for preventing thromboembolic events in Italian patients with non-valvular atrial fibrillation (NVAF). METHODS: Estimated Italian population of patients was run through a previously published lifetime decision tree/Markov model simulating their treatment with the available therapeutic options: dabigatran at two dose levels $(110 \mathrm{mg} / \mathrm{bid}$ for the over 80 years old, $150 \mathrm{mg} /$ bid for younger NVAF patients), rivaroxaban (20 mg/uid), and apixaban (5 mg/bid). Effectiveness and safety estimates derive from an adjusted indirect treatment comparison using warfarin as link. The main clinical events considered in the model are ischemic and hemorrhagic stroke, systemic thromboembolism, bleeds (both major and clinically relevant minor) and cardiovascular hospitalizations, besides treatment discontinuations. Epidemiological data and unit costs, actualized to 2013, are collected from Italian published sources. The budget impact analysis evaluates the financial impact of apixaban introduction by comparing expected 1,2, and 3 years costs in hypothetical scenarios: with and without apixaban. Italian NVAF patient population estimation is based on official apixaban reimbursement criteria, applying the characteristics of the trial population to national epidemiologic data. Numbers of patients for each regimen are estimated by projecting share evolution. Sensitivity analysis is performed on an alternative non-experimental population of NVAF patients.

RESULTS: Among available NOACs, apixaban was expected to be the least expensive in an estimated patient population of 364,000 Italian patients, allowing for savings of $€ 1,180,549, € 3,841,429$ and $€ 5,368,918$ at 1,2, and 3 years, respectively. Results of the simulation run on an alternative non-experimental population of NVAF patients yields comparable estimates. CONCLUSIONS: The different safety and effectiveness profiles of the three available NOACs emerging from the adjusted indirect comparison indicate that apixaban could improve health care expenditure control while maintaining or increasing therapeutic appropriateness in the Italian NVAF population.
\end{abstract}

\section{Keywords}

Apixaban; Novel oral anticoagulant agents; Atrial fibrillation

\section{INTRODUCTION}

Atrial fibrillation (AF) is the most prevalent form of arrhythmia, involving about $1-2 \%$ of the population in industrialized countries [1]. Its prevalence increases with age, reaching values above $5 \%$ in the over 65 years old, and of $9 \%$ in octogenarians [2].

In Italy, a prevalence of 600,000 AF patients was estimated for year 2010, and a further increase is expected due to the increasing age of the population and the improved survival of cardiovascular patients [3]. Stroke is the main complication of $\mathrm{AF}$ [4]: over
$20 \%$ of ischemic strokes are linked to some form of arrhythmia [1], and in these patients, they tend to be more severe than in non-arrhythmic patients [5]. About $40 \%$ of stroke survivors presents moderate to severe disability; applying these rates to the prevalent population, it has been calculated that around 384,000 are not autonomous in Italy due to stroke, and this figure is expected to rise up to 440,000 by 2020 [6].

Therapeutic goals in the management of AF patients include symptom control, but also the prevention of thromboembolic complica-
Corresponding author Lorenzo Pradelli

I.pradelli@adreshe.com

Disclosure

Study funded by

Bristol-Myers Squibb

and Pfizer 
tions, stroke in primis. This was traditionally pursued with the administration of vitamin $\mathrm{K}$ antagonists (VKA), or with antiplatelet agents, mainly aspirin, in subjects intolerant or contraindicated to VKAs [7]. In the last years, however, the class of novel oral anticoagulant agents (NOACs) has been introduced, which is associated with a more favourable risk/benefit ratio than VKAs. Until recently, dabigatran, a direct thrombin inhibitor, and rivaroxaban, a direct and selective coagulation factor Xa inhibitor, were the only NOACs licensed for thromboembolic prevention in non-valvular AF (NVAF, about $70 \%$ of all AF cases). Apixaban, also a direct and selective coagulation factor $\mathrm{Xa}$ inhibitor [8], is facing the launch on the market for this indication, with the following reimbursement restrictions: NVAF with both $\mathrm{CHA}_{2} \mathrm{DS}_{2}-\mathrm{VASc} \geq 1^{1}$ and HAS-BLED $>3^{2}$, or time in therapeutic range (TTR) $<70 \%$ or objective difficulties in measuring INR [9]. Aim of the present analysis is the comparative, short-term economic evaluation of the use of the three available NOACs in the prevention of thromboembolic events in the indicated Italian population of patients with NVAF. A budget impact analysis for the Italian National Health Service, which covers both the pharmaceutical cost and the costs for management of clinical events is performed to evaluate the financial impact following the entry of apixaban among NOACs.

\section{METHODS}

The analysis is conducted with a simulation study, performed through the adaptation and run of an international previously published model $[10,11]$ and executed with epidemiological, clinical practice and unit costs pertinent to the Italian setting. The model is designed to reproduce the experience of a cohort of NVAF patients of user defined features, alternatively treated with the available therapeutic options: for the present study, dabigatran at two dose levels $(110 \mathrm{mg} / \mathrm{bid}$ for the over 80 years old, $150 \mathrm{mg} / \mathrm{bid}$ for

\footnotetext{
1 Calculates stroke risk for patients with atrial fibrillation, possibly better than the CHADS score. It is composed of 7 domains: age (1 point for ages 65-74, 2 points for $>74$ ); gender (Female, 1 point); congestive heart failure history (yes, 1 point); hypertension history (yes, 1 point); stroke/TIA thromboembolism history (yes, 2 points), vascular disease history (yes, 1 point), and diabetes mellitus (yes, 1 point).

2 HAS-BLED is an acronym for: Hypertension, Abnormal Liver/Renal Function, Stroke History, Bleeding Predisposition, Labile INR, Elderly (Age > 65), Drugs/Alcohol Usage, with each of the domains scored 1 point if present, to be added up to obtain total score, which correlates with the risk of major bleeding. Estimates risk of major bleeding for patients on anticoagulation to assess risk-benefit in atrial fibrillation care.
}

younger NVAF patients), rivaroxaban, and apixaban. During the simulation, events and consumed resources from the Italian National Health System perspective are recorded by the model; main clinical outcomes monitored are ischemic and hemorrhagic stroke, systemic thromboembolism, bleeds (both major and clinically relevant minor), cardiovascular hospitalizations, and death.

\section{Model structure}

The model is designed as a decision tree with Markov chains as branches; the experience of a NVAF patient is divided and represented in 17 possible and mutually exclusive health states (Figure 1). Transitions among health states are determined by probability matrices derived from the relevant literature as detailed elsewhere [11].

At the end of each 6 week cycle, patients can stay in the current health state, or experience a clinical event and forward to the corresponding state; some events only imply a resource consumption, whilst others - i.e. stroke, myocardial infarction (MI), and systemic embolism - also modify the chance of incurring in further events. Stroke survivors distribute among subsequent health states basing on the assigned severity distribution of the specific event. Following a major bleeding, patients may continue to receive the initial anticoagulant, or switch to a second line treatment, associated with specific clinical event risks.

\section{Population}

The simulation is run on two cohorts (Table I): the first (base-case) reproducing clinical and demographic features of the ARISTOTLE trail population [12], the second those of a non-experimental population of NVAF patients studied by Olesen et al. [13]. In this cohort study, Olesen et al. assessed the individual risk factors composing the $\mathrm{CHADS}_{2}$ and $\mathrm{CHA}_{2} \mathrm{DS}_{2}$-VASc score calculating the capability of the schemes to predict thromboembolism in a nationwide cohort of Danish real-world patients.

\section{Clinical outcomes rates}

In general, the model assigns baseline clinical risks basing on the demographic and clinical features of the patients; these risks evolve according to the time elapsed from the beginning of the simulation, to the risk-modifying clinical events experienced by the patient, and to the preventive regimen administered. The effectiveness and safety profile of apixaban reflects event rates recorded in the ARISTOTLE trial [12] integrated with patient-level data made available by Lip et al. [11], 


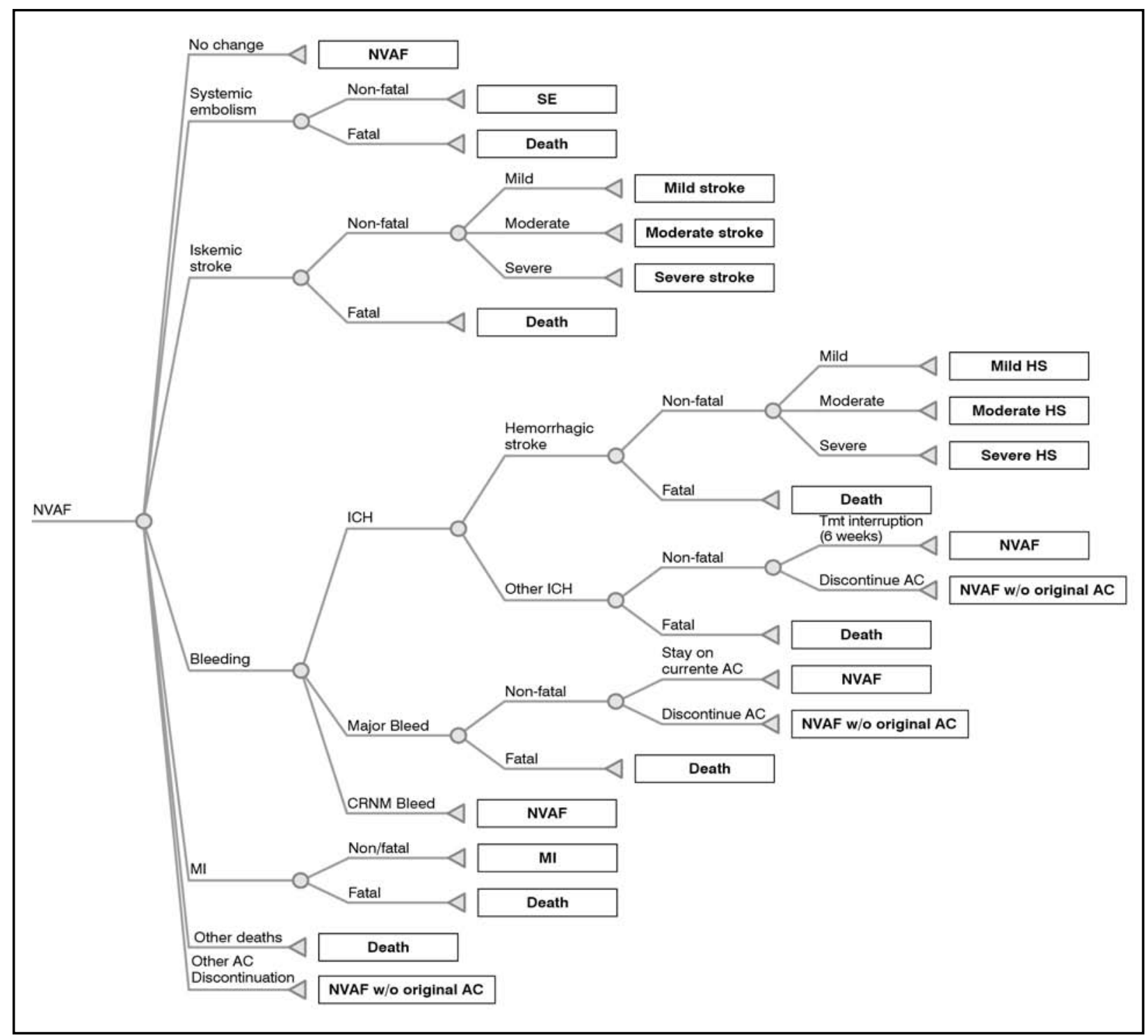

Figure 1. Simplified structure of the Markov model

which showed that apixaban was associated with a reduction in the risk of stroke or systemic embolism, in bleeding, and in all-cause mortality in AF patients, as compared to warfarin. The choice of the ARISTOTLE trial, a randomised head-to-head clinical trial, is related to the comparator, warfarin, which is common to the pivotal trials in $\mathrm{AF}$ of the other NOACs. The baseline risk profile can be adjusted for different distributions in the simulated population vs. the ARISTOTLE population of the $\mathrm{CHADS}_{2}$ and TTR, for stroke and bleeding, respectively.

Dabigatran was compared to warfarin in $\mathrm{AF}$ patients in the RELY trial, in which it demonstrated similar efficacy in stroke and thromboembolic prevention and lower bleeding risk, at the $110 \mathrm{mg}$ bid, and superior stroke and embolism prevention, with similar bleeding risk, at the $150 \mathrm{mg}$ bid dose [14].

Rivaroxaban was compared to warfarin in the ROCKET-AF trial, demonstrating non inferi-

\begin{tabular}{lcc}
\hline & $\begin{array}{c}\text { Base-case - ARISTOTLE } \\
\text { population [12] }\end{array}$ & $\begin{array}{c}\text { Alternative case - } \\
\text { Real-world population [13] }\end{array}$ \\
\hline \% males & 65 & 53 \\
Mean age (years) & 70 & 77 \\
CHADS , score (\%) $^{2}$ & & \\
$0-1$ & 34 & 53 \\
2 & 36 & 23 \\
$>2$ & 30 & 24 \\
\hline
\end{tabular}

Table I. Baseline characteristics of the simulated populations: base-case patient populations, from ARISTOTLE trial [12], and alternative-case population, from a nationwide cohort of real-world patients, registered in the Danish patient registry [13]

ority in the prevention of stroke and thromboembolism in NVAF patients, and similar bleeding risk [15].

Data from the VKA-suitable population of these trials (ARISTOTLE, RELY, and ROCKET-AF) were included in indirect treatment comparisons, using warfarin as common comparator, to obtain relative risks 


\begin{tabular}{|c|c|c|c|c|c|}
\hline & $\begin{array}{c}\text { Apixaban } \\
{[10,11]}\end{array}$ & $\begin{array}{c}\text { Dabigatran } \\
(110 \mathrm{mg}) \text { [11] }\end{array}$ & $\begin{array}{c}\text { Dabigatran } \\
\text { (150 mg) [11] }\end{array}$ & Rivaroxaban [11] & $\begin{array}{c}\text { Aspirin (2nd line) } \\
{[10,11]}\end{array}$ \\
\hline \multicolumn{6}{|l|}{ IS* } \\
\hline Rate/100 pts-yr & 0.98 & & & & $3.45^{6}$ \\
\hline HR (95\% Cl) vs. apixaban & & $1.20(0.88-1.64)$ & $0.82(0.59-1.14)$ & $0.98(0.72-1.33)$ & \\
\hline \multicolumn{6}{|l|}{ Pts distribution (\%) } \\
\hline - Mild mRS (0-2) & 53 & 35 & 35 & 49 & $36^{5}$ \\
\hline - Moderate mRS (3-4) & 21 & 28 & 22 & 18 & $38^{5}$ \\
\hline - Severe mRS (5) & 8 & 10 & 8 & 6 & $15^{5}$ \\
\hline • Fatal mRS (6) & 18 & 27 & 35 & 27 & $11^{5}$ \\
\hline \multicolumn{6}{|l|}{$\mathrm{ICH}^{*}$} \\
\hline Rate/100 pts-yr & 0.33 & & & & $0.32^{6}$ \\
\hline HR (95\% Cl) vs. apixaban & & $0.73(0.43-1.26)$ & $1.02(0.62-1.68)$ & $1.73(1.08-2.77)$ & \\
\hline Other ICH (\%) & 23 & 36 & 59 & 43 & $45^{5}$ \\
\hline Case Fatality Rates (\%) & $13^{3}$ & $13^{2}$ & $13^{2}$ & $13^{2}$ & $13^{5}$ \\
\hline Proportion of HS (\%) & 77 & 64 & 41 & 57 & $55^{5}$ \\
\hline - Mild mRS (0-2) & 23 & 35 & 35 & 49 & $7^{5}$ \\
\hline - Moderate mRS (3-4) & 32 & 28 & 22 & 18 & $20^{5}$ \\
\hline - Severe mRS (5) & 10 & 10 & 8 & 6 & $27^{5}$ \\
\hline • Fatal mRS (6) & 35 & 27 & 35 & 27 & $46^{5}$ \\
\hline \multicolumn{6}{|l|}{ Other MB* } \\
\hline Rate/100 pts-yr & 1.79 & & & & $0.89^{6}$ \\
\hline HR (95\% Cl) vs. apixaban & & $1.21(0.97-1.50)$ & $1.37(1.10-1.70)$ & $1.44(1.15-1.79)$ & \\
\hline Case Fatality Rates & $2^{3}$ & $2^{2}$ & $2^{2}$ & $2^{2}$ & $2^{5}$ \\
\hline Proportion of GI Bleeds & 38 & 41 & 49 & 45 & $39^{5}$ \\
\hline \multicolumn{6}{|l|}{ CRNM* } \\
\hline Rate/100 pts-yr & 2.08 & & & & $2.94^{6}$ \\
\hline HR (95\% Cl) vs. apixaban & & $1.16(0.99-1.35)$ & $1.30(1.11-1.53)$ & $1.49(1.26-1.76)$ & \\
\hline \multicolumn{6}{|l|}{ MI* } \\
\hline Rate/100 pts-yr & 0.53 & & & & $1.11^{6}$ \\
\hline HR (95\% Cl) vs. apixaban & & $1.474(0.96-2.27)$ & $1.46(0.95-2.24)$ & $0.94(0.64-1.38)$ & \\
\hline \multicolumn{6}{|l|}{ SE } \\
\hline Rate/100 pts-yr & 0.09 & & & & $0.40^{4}$ \\
\hline HR (95\% Cl) vs. apixaban & & $1^{2}$ & $1^{2}$ & $1^{2}$ & \\
\hline \multicolumn{6}{|l|}{ Other CV Hosp } \\
\hline Rate/100 pts-yr & $10.46^{1}$ & & & & $13.57^{6}$ \\
\hline HR (95\% Cl) vs. apixaban & & $1^{2}$ & $1^{2}$ & $1^{2}$ & \\
\hline \multicolumn{6}{|l|}{ Other Treat Disc } \\
\hline Rate/100 pts-yr & 13.18 & & & & - \\
\hline HR (95\% Cl) vs. apixaban & & $1.45(1.31-1.61)$ & $1.51(1.36-1.67)$ & $1.18(1.08-1.29)$ & \\
\hline \multicolumn{6}{|l|}{ Background mortality ${ }^{\circ}$} \\
\hline Rate/100 pts-yr & 3.08 & & & & - \\
\hline HR (95\% Cl) vs. apixaban & & $1^{2}$ & $1^{2}$ & $1^{2}$ & \\
\hline
\end{tabular}

Table II. Summary of main clinical inputs used in the analysis

CRNM: Clinically Relevant non Major Bleeds; Gl: Gastro-Intestinal Bleeds; HS: Hemorrhagic Stroke; ICH: IntraCranial Hemorrhages; IS: Ischemic Stroke; MI: Myocardial Infarction; Other CV Hosp: Other Cardio-Vascular Hospitalization; Other MB: other Major Bleeds; Other TreatDisc: Other Treatment Discontinuation; pts: patients; SE: Systemic Embolism; yr: year

${ }^{1}$ Assume same rate as the apixaban's rate observed among the VKA unsuitable population

${ }^{2}$ Assume same risk as apixaban

${ }^{3}$ Pooled sample percentages

${ }^{4}$ Assume same rate as ASA first line observed in the VKA unsuitable population

${ }^{5}$ Assume same distribution as ASA first line

'Subgroup of patients who had VKA-unsuitability "demonstrated" (i.e., previously failed warfarin)

* Stroke, bleeds and Ml risks are adjusted over time to take into account the increased risks with aging: HR for adjunctive decade of 1.4 [16], 1.97 [17], and 1.3 [20], respectively, are applied

${ }^{\circ}$ For the duration of the trial follow-up 


\begin{tabular}{|c|c|c|c|c|c|c|c|}
\hline \multirow{2}{*}{$\begin{array}{l}\text { Health } \\
\text { condition }\end{array}$} & \multirow{2}{*}{ NVAF [23] } & \multicolumn{3}{|c|}{ Stroke [24-26] } & \multicolumn{2}{|c|}{ MI [27] } & \multirow{2}{*}{$S^{*}$} \\
\hline & & Mild & Moderate & Severe & Female & Male & \\
\hline HR & 1.34 & 3.18 & 5.84 & 15.75 & 4.16 & 2.56 & 1.34 \\
\hline
\end{tabular}

Table III. Death hazard ratios according to the health condition of the simulated patient

* Assumption

or hazard ratios of each of the NOACs vs. apixaban, for each evaluated outcome [11] (Table I).

For apixaban, the risk of incurring an ischemic stroke (IS) is directly extrapolated from the ARISTOTLE in the base-case analysis, and adjusted for the $\mathrm{CHADS}_{2}$ distribution in Olesen et al. [13] for the alternative scenario; for the competing NOACs, the rate is calculated by applying the relevant HR to the apixaban hazard in both analyses. Increasing age is associated with higher IS risk; in the model, this is accounted for by applying a HR of 1.4 per decade [16]. Severity distribution of IS is classified according to the modified Rankin scale (mRS - mild 0-2; moderate $3-4$; severe 5 and fatal 6) specific to the AC treatment and was derived from published literature (Table II).

As with IS, in the base-case analysis the absolute intracranial hemorrhage (ICH) hazard rate for apixaban is directly obtained from ARISTOTLE; specific HRs are applied to these rates to determine the hazard rates for dabigatran and rivaroxaban. The model accounts for age-related increase in ICH risk by applying a $1.97 \mathrm{HR}$ per decade [17]. Hemorrhagic strokes (HS) are determined as a treatment-specific percentage of ICHs; similarly, their severity distribution, again expressed in terms of mRS, is treatment-specific.

IS and HS survivors are at risk of recurrence: this is modelled according to a real-life registry indicating a cumulative incidence of 4.1 and 3.0 per 100 patient-years, respectively [18]; the severity distribution of recurrent strokes for all alternatives is conditional on the severity of the first stroke, as observed in ARISTOTLE and AVERROES [19].

As with IS and ICH, the model accounts for increasing MI risk with higher ages by applying an HR of 1.30 per decade [20]. MI case fatality rates applied in the simulation are specific for gender $(10.8 \%$ in men and $15.6 \%$ for women), differently than for SE (9.4\%) [21]. During the simulation, patients may discontinue treatment, either completely, or by switching to another AC regimen, as a consequence of clinical events incurred, or for other reasons as described on Dorian et al. [10] and Lip et al. [11]

Besides the already described case fatality rates for stroke, bleeding, and MI, the popu- lation is subjected to a background mortality derived from ARISTOTLE for the duration of the trial follow-up; given the lack of sound comparative mortality rates, the same background mortality has been applied to all NOACs.

Beyond the trial duration, mortality is projected based on Gompertz distributions fitted on Italian age- and gender-specific population rates [22], corrected for the HRs associated to $\mathrm{AF}, \mathrm{MI}$, stroke, and $\mathrm{SE}$, as shown in Table III.

\section{costs}

Costs are evaluated from the perspective of the National Health System (SSN); accordingly, only direct health care costs are considered:

- Drug acquisition costs, at negotiated net prices [28] (Table IV);

- Routine visits [29] for all treated patients;

- Acute event management (strokes, bleeds, myocardial infarction, and other CV hospitalizations);

- Long-term post-event management for stroke, MI, and SE;

- Other health care costs associated with AC management (Table V).

Stroke management costs have been elaborated basing on data reported in an observational study conducted on 411 Italian stroke survivors, followed up for 12 months [30]: for each severity category within ischemic and hemorrhagic strokes, the mean long-term maintenance cost has been approximated to the monthly cost recorded in the second semester; the costs for the acute phase correspond to the sum of the corresponding DRG tariff [31] and the difference between the costs accrued in the first and second follow-up semester.

\begin{tabular}{lcc}
\hline \multicolumn{1}{c}{ Drug } & Daily dose (mg/die) & Daily cost (€) \\
\hline Aspirin & 100 & 0.04 \\
Apixaban & 10 & 1.90 \\
Dabigatran (110 mg) & 220 & 1.90 \\
Dabigatran $(150 \mathrm{mg})$ & 300 & 1.90 \\
Rivaroxaban & 20 & 1.80 \\
\hline
\end{tabular}

Table IV. Drug acquisition costs, at negotiated net prices [28] 


\begin{tabular}{|c|c|c|c|c|}
\hline & Unit cost $(€)$ & Unit & Duration & Source \\
\hline \multicolumn{4}{|l|}{ Ischemic Stroke } & Lucioni et al. [29] \\
\hline \multicolumn{5}{|l|}{ Mild } \\
\hline - Acute & $4,663.06$ & per episode & 2 weeks & Fattore et al. [30] \\
\hline - Maintenance & 81.76 & per month & Simulation length & Fattore et al. [30] \\
\hline \multicolumn{5}{|l|}{ Moderate } \\
\hline - Acute & $6,137.96$ & per episode & 2 weeks & Fattore et al. [30] \\
\hline - Maintenance & 139.04 & per month & Simulation length & Fattore et al. [30] \\
\hline \multicolumn{5}{|l|}{ Severe } \\
\hline - Acute & $10,311.34$ & per episode & 2 weeks & Fattore et al. [30] \\
\hline - Maintenance & 327.95 & per month & Simulation length & Fattore et al. [30] \\
\hline Fatal & $3,891.00$ & per episode & $\mathrm{N} / \mathrm{A}$ & DRG 14 [31] \\
\hline \multicolumn{5}{|l|}{ Hemorrhagic stroke } \\
\hline \multicolumn{5}{|l|}{ Mild } \\
\hline - Acute & $6,321.14$ & per episode & 2 weeks & Fattore et al. [30] \\
\hline - Maintenance & 118.11 & per month & Simulation length & Fattore et al. [30] \\
\hline \multicolumn{5}{|l|}{ Moderate } \\
\hline - Acute & $10,073.43$ & per episode & 2 weeks & Fattore et al. [30] \\
\hline - Maintenance & 200.86 & per month & Simulation length & Fattore et al. [30] \\
\hline \multicolumn{5}{|l|}{ Severe } \\
\hline - Acute & $20,932.42$ & per episode & 2 weeks & Fattore et al. [30] \\
\hline - Maintenance & 473.77 & per month & Simulation length & Fattore et al. [30] \\
\hline Fatal & 3,891 & per episode & $\mathrm{N} / \mathrm{A}$ & DRG 14 [31] \\
\hline Other ICH & 25,812 & per episode & $\mathrm{N} / \mathrm{A}$ & DRG 528 [31] \\
\hline Other major bleeding & 3,317 & per episode & $\mathrm{N} / \mathrm{A}$ & DRG 174 [31] \\
\hline CRNMB & 2,091 & per episode & N/A & DRG 175 [31] \\
\hline \multicolumn{5}{|l|}{ IM } \\
\hline - Acute & $6,275.21$ & per episode & $\mathrm{N} / \mathrm{A}$ & Mantovani et al. [32] \\
\hline - Maintenance & 157.97 & per month & Simulation length & Mantovani et al. [32] \\
\hline \multicolumn{5}{|l|}{ SE } \\
\hline - Acute & $4,663.06$ & per episode & 2 weeks & Assumption \\
\hline - Maintenance & 81.76 & per month & Simulation length & Assumption \\
\hline Other CV hospitalization & 4,742 & per episode & $\mathrm{N} / \mathrm{A}$ & DRG 479 [31] \\
\hline
\end{tabular}

Table V. Cost inputs

For acute and long-term MI management, cost data are elaborated basing on three-year follow-up data reported for Italian MI survivors [32]. The costs attributed to the other clinical events considered are equalled to the corresponding DRG-based tariff paid to hospitals by the Italian NHS [31].

Other AC related costs considered are related to dyspepsia management ( $€ 71.46 /$ year [33], rates of dyspepsia from ARISTOTLE for apixaban and warfarin, from adjusted indirect comparison for dabigatran, and assumed equal to apixaban for rivaroxaban) and to renal function monitoring for dabigatran treated patients at risk $(19.4 \%$, according to RELY data), equalled to the corresponding tariff of $€ 8.16$ [31].

All historical cost data have been actualized to 2013 values using official indices [22] (Table V).

\section{Budget impact analysis}

The budget impact analysis evaluates the financial impact of apixaban introduction by comparing expected 1,2, and 3 years cost in two hypothetical scenarios: with and without apixaban.

Total, undiscounted costs per patient estimated by the simulation for the considered regimens are applied to the corresponding 
market shares estimated for the two scenarios at 1,2, and 3 years. Numbers of patients for each regimen are estimated by projecting share evolution based on IMS market research [34].

\section{RESULTS}

In Table VI, main results of the simulation for all alternatives at 1,2, and 3 years are shown: among available NOACs, it can be seen that apixaban results the least expensive in all considered years.

The target population is estimated in about 364,000 patients (Table VII), calculated by applying a $1.7 \%$ AF prevalence rate [35], of which $70 \%$ are NVAF subjects, to the Italian resident population, and considering that about $50 \%$ satisfy the criteria for reimbursement issued by AIFA, i.e. $\mathrm{CHA}_{2} \mathrm{DS}_{2}-\mathrm{VASc} \geq 1$ and HAS-BLED > $3(9,38 \%)$ [36,37], or TTR $<70 \%(40 \%)$ [38] or objective difficulties in measuring INR.

It has to be noted that the eligible patient population identified by AIFA through these criteria appears inconsistent with the assigned pharmaceutical expense cap for the class, indicated by AIFA itself in $60 \mathrm{M} € /$ year: it can be easily calculated (basing on an approximate cost of $650 € /$ year per patient) that this budget is sufficient to cover a maximum of about one fourth of the patients who are expected to benefit the most from the availability of the innovative NOACs.

The expected penetration of NOACs on the market in the next three years has been estimated based on the market evolution from the approval of NVAF as indication for the NOACs (Table VIII); in the scenario in which apixaban is present, an increasing percentage of the NOAC - treated population is prescribed apixaban, with shares subtracted proportionally to the comparators, as shown in Table VIII. Cumulative cost estimates, as estimated by the model and shown in detail in Table VI are applied to the resulting patient numbers for each regimen and added up to obtain the expected budget dedicated to the target population: the budget impact is calculated as the difference among the total costs expected without and with the introduction of apixaban.

Resulting patient numbers per regimen are displayed in Table VIII, alongside the expected cumulative impact: under the detailed assumptions, the introduction of apixaban will temper the cost associated with expanding market shares of NOACs, allowing for savings of over 5 million $€$ by the third year. Main results of the simulation run on non-experimental population of NVAF pa-

\begin{tabular}{lccc}
\hline \multirow{2}{*}{ Strategy } & \multicolumn{3}{c}{ Total cost $(\boldsymbol{\epsilon})$} \\
\cline { 2 - 4 } & Year $\mathbf{1}$ & Year $\mathbf{2}$ & Year 3 \\
\hline Apixaban & 1,425 & 2,961 & 4,436 \\
Dabigatran (110 mg) & 1,449 & 2,992 & 4,461 \\
Dabigatran (150 mg) & 1,459 & 3,007 & 4,476 \\
Rivaroxaban & 1,459 & 3,020 & 4,511 \\
\hline
\end{tabular}

Table VI. Base-case: main simulation results

\begin{tabular}{lccc}
\hline & $\%$ & $\mathbf{N}$ & Source \\
\hline $\begin{array}{l}\text { Residents in Italy } \\
\text { AF Prevalence }\end{array}$ & 1.70 & $1,039,982$ & $\begin{array}{c}\text { ISTAT [22] } \\
\text { Bollettino Ufficiale } \\
\text { Regione Veneto [35] }\end{array}$ \\
NVAF & 70 & 727,987 & ESC, 2010 [1] \\
AlFA criteria* & 50 & 363,994 & $\begin{array}{c}\text { Friberg, 2012 [36]; } \\
\text { ATA-AF, 2013 [37]; } \\
\end{array}$ \\
& & & Nichol, 2008 [38] \\
\hline
\end{tabular}

Table VII. Target population per BI

* About $50 \%$ of patients satisfy the criteria for reimbursement issued by AIFA: NVAF with both $\mathrm{CHA}_{2} \mathrm{DS}_{2}-\mathrm{VASC} \geq 1$ and HAS-BLED $>3$, or time in therapeutic range (TTR) $<70 \%$ or objective difficulties in measuring INR

\begin{tabular}{lccc}
\hline & Year 1 & Year 2 & Year 3 \\
\hline Common scenario & & & \\
Target pts (n.) & 363,994 & 363,994 & 363,994 \\
NOACs & & & \\
• n. & 71,204 & 133,481 & 150,559 \\
• \% & 20 & 37 & 41 \\
Warfarin & & & \\
• n. & 292,790 & 230,513 & 213,435 \\
• \% & 80 & 63 & 59 \\
Scenario w/o apixaban & & & \\
Dabigatran 110 mg (n.) & 20,107 & 36,551 & 40,654 \\
Dabigatran 150 mg (n.) & 25,383 & 46,144 & 51,323 \\
Rivaroxaban (n.) & 25,714 & 50,786 & 58,582 \\
Apixaban (n.) & 0 & 0 & 0 \\
Scenario w/ apixaban & & & \\
Dabigatran 110 mg (n.) & 9,414 & 14,093 & 11,407 \\
Dabigatran 150 mg (n.) & 11,884 & 17,792 & 14,401 \\
Rivaroxaban (n.) & 12,039 & 19,582 & 16,437 \\
Apixaban (n.) & 37,867 & 82,014 & 108,314 \\
BI (€) & $\mathbf{- 1 , 1 8 0 , 5 4 9}$ & $\mathbf{- 3 , 8 4 1 , 4 2 9}$ & $\mathbf{- 5 , 3 6 8 , 9 1 8}$ \\
\hline
\end{tabular}

Table VIII. Base-case - Budget impact

tients [13] for all alternatives at 1, 2, and 3 years are presented in Table IX. Resulting expected financial impact obtained by applying these results to the identified target population are displayed in Table $\mathrm{X}$, and substantially confirm the estimates of the base-case analysis. 


\begin{tabular}{lccl}
\hline \multirow{2}{*}{\multicolumn{1}{c}{ Regimen }} & \multicolumn{3}{c}{ Total cost $\boldsymbol{(} \boldsymbol{(})$} \\
\cline { 2 - 4 } & Year $\mathbf{1}$ & Year $\mathbf{2}$ & Year 3 \\
\hline Apixaban & 1,419 & 2,942 & 4,366 \\
Dabigatran (110 mg) & 1,441 & 2,971 & 4,385 \\
Dabigatran (150 mg) & 1,454 & 2,992 & 4,413 \\
Rivaroxaban & 1,453 & 3,004 & 4,445 \\
\hline
\end{tabular}

Table IX. Real world population [13] - main simulation results

\begin{tabular}{lccc}
\hline \multicolumn{1}{l}{ Year 1 } & Year 2 & Year 3 \\
\hline Common scenario & & & \\
Target pts (n.) & 363,994 & 363,994 & 363,994 \\
NOACs & & & \\
• n. & 71,204 & 133,481 & 150,559 \\
•\% & 20 & 37 & 41 \\
Warfarin & & & \\
• n. & 292,790 & 230,513 & 213,435 \\
• \% & 80 & 63 & 59 \\
Scenario w/o apixaban & & & \\
Dabigatran 110 mg (n.) & 20,107 & 36,551 & 40,654 \\
Dabigatran 150 mg (n.) & 25,383 & 46,144 & 51,323 \\
Rivaroxaban (n.) & 25,714 & 50,786 & 58,582 \\
Apixaban (n.) & 0 & 0 & 0 \\
Scenario w/ apixaban & & & \\
Dabigatran 110 mg (n.) & 9,414 & 14,093 & 11,407 \\
Dabigatran 150 mg (n.) & 11,884 & 17,792 & 14,401 \\
Rivaroxaban (n.) & 12,039 & 19,582 & 16,437 \\
Apixaban (n.) & 37,867 & 82,014 & 108,314 \\
BI (€) & $\mathbf{- 1 . 1 9 0 . 2 9 6}$ & $\mathbf{- 3 . 9 7 1 . 1 5 1}$ & $\mathbf{- 5 . 5 6 8 . 7 8 5}$ \\
\hline
\end{tabular}

Table X. Real world population [13] - budget impact analysis

A comparison of total costs accruing after three years for the treatment of the whole identified patient population with one of the available NOACs is presented in Table XI, in order to highlight the total potential budget impact of systematically choosing just one of the NOAC for this indication, and to detail how the different cost components are affected by such a choice. The excess pharmaceutical cost, due to improved persistence with the prescribed $\mathrm{AC}$ regimen with apixaban, is completely offset by reduced costs for event management, leading to the overall per patient saving already shown in Table VI.

\section{CONCLUSIONS}

The expected economic differences among NOACs stem from the different safety and effectiveness profile of the NOACs emerging from the adjusted indirect comparison.

Dabigatran, at the $110 \mathrm{mg}$ BID dose, appears associated with a lower ICH risk than apixaban, but this should be traded off with an apparently reduced protection against ischemic strokes; the latter may be mitigated with the higher dabigatran dose (150 mg BID) or with the use of rivaroxaban, but at the expense of much higher bleeding risks; however from a health economics point of view, neither trade-off is expected to be efficient.

In conclusion, analyses based upon demonstrated relative effectiveness and safety profiles indicate that the different balance between ischemic protection and increased bleeding risk is more favourable with apixaban than with the other NOACs from a health economics perspective: the pharmacoeconomic analyses performed and the findings presented in this paper clearly support the value of apixaban in Italian NVAF patients.

Its use in these patients, when compared with other NOACs, is expected to have the potential for relevant savings (between $€ 8.8$ million and $€ 27.3$ million), which are linked to its intrinsic effectiveness and to the lowest discontinuation rate among its class members (it is known that to maintain preventive effectiveness, NOACs have to be taken regularly by the patients).

\begin{tabular}{lccc}
\hline \multirow{2}{*}{ Cost $(\boldsymbol{\epsilon})$} & \multicolumn{3}{c}{ Delta apixaban vs. } \\
\cline { 2 - 4 } & Dabigatran (110 $\mathbf{~ g )}$ & Dabigatran $\mathbf{( 1 5 0} \mathbf{~ m g})$ & Rivaroxaban \\
\hline Anticoagulants & $49,632,106$ & $55,842,014$ & $52,540,069$ \\
Ischemic Stroke & $-24,362,893$ & $-922,257$ & $-365,284$ \\
Hemorrhagic Stroke & $9,372,101$ & $12,084,733$ & $-3,367,459$ \\
Systemic Embolism & $-973,544$ & $-1,137,583$ & $-459,840$ \\
Other bleedings & $-16,016,517$ & $-50,508,295$ & $-73,677,525$ \\
MI + CV hospitalizations & $-24,207,752$ & $-27,540,021$ & $-2,158,969$ \\
Other* & $-2,276,000$ & $-2,265,143$ & 206,011 \\
Total cost & $\mathbf{- 8 , 8 3 2 , 5 0 0}$ & $\mathbf{- 1 4 , 4 4 6 , 5 5 1}$ & $\mathbf{- 2 7 , 2 8 2 , 9 9 8}$ \\
\hline
\end{tabular}

Table XI. Potential Bl at three years, detailed by component $(n .=363,994)$

* Other costs include routine care visit and health care costs associated with AC management 


\section{REFERENCES}

1. European Heart Rhythm Association, European Association for Cardio-Thoracic Surgery, Camm AJ, et al. Guidelines for the management of atrial fibrillation: the Task Force for the Management of Atrial Fibrillation of the European Society of Cardiology (ESC). Eur Heart J 2010; 31: 2369-429; http://dx.doi.org/10.1093/eurheartj/ehq278

2. Kannel WB, Benjamin EJ. Status of the epidemiology of atrial fibrillation. Med Clin North Am 2008; 92: 17-40; http://dx.doi.org/10.1016/j.mcna.2007.09.002

3. Wolf CD, Rudd AG. The Burden of Stroke White paper: Raising awareness of the global toll of stroke-related disability and death

4. Wolf PA, Abbott RD, Kannel WB. Atrial fibrillation as an independent risk factor for stroke: the Framingham Study. Stroke 1991; 22: 983-8; http://dx.doi.org/10.1161/01.STR.22.8.983

5. Lamassa M, Di Carlo A, Pracucci G, et al. Characteristics, outcome, and care of stroke associated with atrial fibrillation in Europe: data from a multicenter multinational hospital-based registry (The European Community Stroke Project). Stroke 2001; 32: 392-8; http://dx.doi.org/10.1161/01.STR.32.2.392

6. Sacchetti MA, Spandonaro F, Finzi G, et al. Prevenzione dell'ictus in Italia - diversità regionali ed assetti. Sole 24 Ore sanità Allegato al n.10 del 15-21 Marzo 2011

7. National Institute for Health and Care Excellence. Atrial fibrillation: the management of atrial fibrillation. NICE Clinical guideline 36. NHS, 2006

8. Summary of Product Characteristics [SPC] of apixaban

9. AIFA. Piano Terapeutico Eliquis ${ }^{\circledR}$ (apixaban)

10. Dorian P, Kongnakorn T, Phatak H, et al. Cost-effectiveness of apixaban vs. current standard of care for stroke prevention in patients with atrial Fibrillation. Eur Heart J 2014; 35: 1897-906; http://dx.doi.org/10.1093/eurheartj/ ehu006

11. Lip GYH, Kongnakorn T, Phatak H, et al. Cost-Effectiveness of Apixaban Versus Other New Oral Anticoagulants for Stroke Prevention in Atrial Fibrillation. Clin Ther 2014; 36: 192-210; http://dx.doi.org/10.1016/j.clinthera.2013.12.011

12. Granger CB, Alexander JH, McMurray JJ, et al. Apixaban versus warfarin in patients with atrial fibrillation. $N$ Engl $J$ Med 2011; 365: 981-92; http://dx.doi.org/10.1056/NEJMoa1107039

13. Olesen JB, Lip GY, Hansen ML, et al. Validation of risk stratification schemes for predicting stroke and thromboembolism in patients with atrial fibrillation: nationwide cohort study. BMJ 2011; 342: d124; http://dx.doi.org/10.1136/ bmj.d124

14. Connolly SJ, Ezekowitz MD, Yusuf S, et al. Dabigatran versus warfarin in patients with atrial fibrillation. $N$ Engl J Med 2009; 361: 1139-51; http://dx.doi.org/10.1056/NEJMoa0905561

15. Patel MR, Mahaffey KW, Garg J, et al. Rivaroxaban versus warfarin in nonvalvular atrial fibrillation. $N$ Engl J Med 2011; 365: 883-91; http://dx.doi.org/10.1056/NEJMoa1009638

16. [No author listed]. Risk factors for stroke and efficacy of antithrombotic therapy in atrial fibrillation. Analysis of pooled data from five randomized controlled trials. Arch Intern Med 1994; 154: 1449-57; http://dx.doi.org/10.1001/ archinte.1994.00420130036007

17. Ariesen M, Claus S, Rinkel G, et al. Risk factors for intracerebral hemorrhage in the general population: a systematic review. Stroke 2003; 34: 2060-5; http://dx.doi.org/10.1161/01.STR.0000080678.09344.8D

18. Mohan KM, Crichton SL, Grieve AP, et al. Frequency and predictors for the risk of stroke recurrence up to 10 years after stroke: the South London Stroke Register. J Neurol Neurosurg Psychiatry 2009; 80: 1012-8; http://dx.doi. org/10.1136/jnnp.2008.170456

19. Connolly S, Eikelboom J, Joyner C, et al. Apixaban in patients with atrial fibrillation. $N$ Engl J Med 2011; 364: 806-17; http://dx.doi.org/10.1056/NEJMoa1007432

20. Freeman JV, Zhu RP, Owens DK, et al. Cost-effectiveness of dabigatran compared with warfarin for stroke prevention in atrial fibrillation. Ann Intern Med 2011; 154: 1-11; http://dx.doi.org/10.7326/0003-4819-154-1-201101040-00289

21. Scarborough P, Bhatnagar P. Coronary Heart Disease statistics 2010 edition; British Health Foundation Health Promotion research group, Department of Public Health, University of Oxford

22. ISTAT. Available at: www.ISTAT.it (last accessed February 2014) 
23. Friberg L, Hammar N, Pettersson H, et al. Increased mortality in paroxysmal atrial fibrillation: report from the Stockholm Cohort-Study of Atrial Fibrillation (SCAF). Eur Heart J 2007; 28: 2346-53; http://dx.doi.org/10.1093/ eurheartj/ehm308

24. Brønnum-Hansen H, Davidsen M, Thorvaldsen P. Long-Term Survival and Causes of Death After Stroke. Stroke 2001; 32: 2131-6; http://dx.doi.org/10.1161/hs0901.094253

25. Henriksson K, Farahmand B, Johansson S, et al. Survival after stroke - The impact of CHADS score and AF. Int J Cardiol 2010; 141: 18-23; http://dx.doi.org/10.1016/j.ijcard.2008.11.122

26. Huybrechts K, Caro J, Xenakis J. The prognostic value of the modified rankin scale score for long-term survival after first-ever stroke. Cerebrovasc Dis 2008; 26: 381-7; http://dx.doi.org/10.1159/000151678

27. Brønnum-Hansen H, Jorgensen T, Davidsen M, et al. Survival and cause of death after myocardial infarction: the Danish MONICA study. J Clin Epidemiol 2001; 54: 1244-50; http://dx.doi.org/10.1016/S0895-4356(01)00405-X

28. Informatore Farmaceutico on-line. Available at: http:/www.codifa.it/ (last accessed February 2014)

29. Lucioni C, Garancini MP, Massi-Benedetti M, et al. The costs of type 2 diabetes mellitus in Italy: a CODE-2 sub-study. Treat Endocrinol 2003; 2: 121-33; http://dx.doi.org/10.2165/00024677-200302020-00005

30. Fattore G, Torbica A, Susi A, et al. The social and economic burden of stroke survivors in Italy: a prospective, incidence-based, multi-centre cost of illness study. BMC Neurology 2012; 12: 137; http://dx.doi. org/10.1186/1471-2377-12-137

31. Remunerazione prestazioni di assistenza ospedaliera per acuti, assistenza ospedaliera di riabilitazione e di lungodegenza post acuzie e di assistenza specialistica ambulatoriale. DM 10/2012 on Gazzetta Ufficiale n. 23 of 1/28/2013

32. Mantovani LG, Fornari C, Madotto F, et al. Burden of acute myocardial infarction. Int J Cardiol 2011; 150: 111-2; http://dx.doi.org/10.1016/j.ijcard.2011.04.030

33. Colombo GL, Caruggi M, Vinci M, et al. Costo sociale annuo della dispepsia funzionale dopo l'eradicazione dell'Helicobacter pylori. PharmacoEconomics - Italian Research Articles 2005; 7: 27-42; http://dx.doi.org/10.1007/ BF03320533

34. IMS Health of MAT September 2012, market shares of anticoagulants in atrial fibrillation (data on-file)

35. Epidemiologia della fibrillazione atriale. Bollettino informativo a cura del Sistema Epidemiologico Regionale del Veneto. Informazione Epidemiologia Salute 2009;VI(4). Available at: www.ser-veneto.it

36. Friberg L, Rosenqvist M, Lip GY. Net clinical benefit of warfarin in patients with atrial fibrillation: a report from the Swedish atrial fibrillation cohort study. Circulation 2012; 125: 2298-3; http://dx.doi.org/10.1161/CIRCULATIONAHA.111.055079

37. Gussoni G, Di Pasquale G, Vescovo G, et al. Decision making for oral anticoagulants in atrial fibrillation: the ATA-AF study. Eur J Intern Med 2013; 24: 324-32; http://dx.doi.org/10.1016/j.ejim.2013.04.008

38. Nichol MB, Knight TK, Dow T, et al, Quality of anticoagulation monitoring in nonvalvular atrial fibrillation patients: comparison of anticoagulation clinic versus usual care. Ann Pharmacother 2008; 42: 62-70; http://dx.doi. org/10.1345/aph.1K157 